\title{
Systemic therapy in patients with NSCLC with brain metastasis: the emerging role of immunotherapy
}

\author{
Jiaxin Niư ${ }^{1}$, Junle Zhou ${ }^{2}$, Sara Lindebak ${ }^{1}$, Fade Mahmoud ${ }^{1}$ \\ 'Department of Medical Oncology, Banner MD Anderson Cancer Center, Gilbert, AZ 85234, USA. \\ 2Department of Pharmacy, Banner MD Anderson Cancer Center, Gilbert, AZ 85234, USA.
}

Correspondence to: Dr. Jiaxin Niu, Department of Medical Oncology, Banner MD Anderson Cancer Center, 2946 E Banner Gateway Dr., Gilbert, AZ 85234, USA. E-mail: jiaxin.niu@bannerhealth.com

How to cite this article: Niu J, Zhou J, Lindebak S, Mahmoud F. Systemic therapy in patients with NSCLC with brain metastasis: the emerging role of immunotherapy. Neuroimmuno/ Neuroinflammation 2018;5:32. http://dx.doi.org/10.20517/2347-8659.2018.39

Received: 13 Jun 2018 First Decision: 18 Jul 2018 Revised: 6 Aug 2018 Accepted: 7 Aug 2018 Published: 23 Aug 2018

Science Editor: Athanassios P. Kyritsis Copy Editor: Jun-Yao Li Production Editor: Huan-Liang Wu

\begin{abstract}
Brain metastasis (BM) is very common in advanced non-small cell lung cancer (NSCLC) patients. The development of BM remains a serious complication associated with significant morbidity and mortality. The traditional approach has been largely focusing on local therapy with surgery and/or radiation. New approaches to treat BM in NSCLC are urgently needed to offer safe and effective therapy as well as to preserve neurocognitive function. There has been significant progress in development of systemic therapies to treat advanced NSCLC in recent years. Targeted therapy has been gradually incorporated into clinical practice to manage NSCLC with BM. Immunotherapy (IO) has revolutionized our treatment paradigm to manage advanced NSCLC. In this review we outline the systemic options for NSCLC-related BM and discuss IO in NSCLC. Finally, we describe the available data and future perspective to support the use of IO in NSCLC patients with BM.
\end{abstract}

Keywords: Immunotherapy, non-small cell lung cancer, brain metastasis

\section{INTRODUCTION}

An estimated 1.8 million new lung cancer cases occurred worldwide in 2012, accounting for approximately $13 \%$ of total cancer diagnoses. Lung cancer is the leading cause of cancer mortality in both men and women in developed countries ${ }^{[1]}$. Roughly $85 \%$ of lung cancers are non-small cell lung cancer (NSCLC) and the 5 -year survival rate in stage IV remains less than $5 \%{ }^{[2]}$. Brain metastasis (BM) has long been recognized to represent a common event in NSCLC. About $10 \%-25 \%$ of NSCLC patients present with BM upon the initial

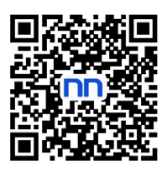


diagnosis, and up to $50 \%$ will develop BM at some point during the course of the disease $e^{[3,4]}$. The incidence of BM appears to have increased in the past decade due to the wide use of magnetic resonance imaging to detect smaller lesions as well as to the evolution of more effective systemic therapy leading to better control of extra-cranial disease and prolonged survival ${ }^{[5,6]}$. Historically, the development of BM is associated with poor prognosis with median overall survival (OS) ranging from 3.4 to 7.1 months after whole brain radiation therapy $(\mathrm{WBRT})^{[7]}$.

\section{LOCAL THERAPY}

Local therapy with surgery and/or radiation therapy has been the mainstay of treatment for decades. For younger patients with a newly diagnosed solitary BM, surgical resection followed by WBRT is supported by level I evidence and incorporated in some clinical guidelines ${ }^{[8]}$. WBRT has been the standard of care for NSCLC patients with multiple BM. This practice was recently called into question. In the QUARTZ trial, WBRT failed to show any survival or quality of life benefit compared with steroid and best supportive care in NSCLC patients with multiple BM, although majority of the patients had poor performance status (PS) ${ }^{[9]}$. On the other hand, WBRT was deemed inadequate in the long-term control of BM in patients with good PS and prolonged survival due to effective systemic therapy. Moreover, these patients may survive long enough to experience significant neurocognitive sequelae associated with WBRT. To avoid neurotoxicity from WBRT, stereotactic radiosurgery (SRS) has been advocated in patients with better prognosis and a limited number of BM. A meta-analysis demonstrated that WBRT with or without SRS did not improve OS compared with SRS alone in patients with up to four BM; whereas SRS was substantially superior in preserving PS and neurocognitive function ${ }^{[10]}$. A Japanese study of SRS alone for patients with one to ten BM showed that distant brain failure rate and survival did not differ significantly in patients with two to four versus five to ten lesions ${ }^{[11]}$. In patients with BM who underwent resection, SRS to the surgical cavity was compared head-to-head with WBRT in a randomized phase 3 study. It demonstrated no difference in OS, but less frequent decline in cognitive function (52\% vs. $85 \%$ at 6 months) in SRS group. Thus, SRS is regarded as one of the standards of care after resection of a brain metastasis ${ }^{[12]}$. For appropriate patients, SRS has been getting increasingly utilized in practice in recent years.

\section{CHEMOTHERAPY}

For years the role of systemic therapy in treating BM in NSCLC patients has been neglected owing to the prevailing belief that therapeutic drugs cannot cross the blood brain barrier. Traditional chemotherapy with platinum-based doublets has been shown in the first-line setting to be active in controlling BM in small studies. The commonly used regimens for adenocarcinoma of a platinum plus pemetrexed were shown in phase 2 studies to demonstrate roughly $40 \%$ intracranial response rate (ICRR), comparable to systemic response rate $e^{[13,14]}$.

\section{TARGET THERAPY}

With recent advances in understanding NSCLC biology, many highly specific target agents have become available, redefining the role of systemic therapy in treating BM in NSCLC. In recent years, several distinct molecular driver mutations have been discovered, and the list is getting longer over time. The most common epidermal growth factor receptor (EGFR) mutation constitutes $10 \%-15 \%$ of lung adenocarcinoma in the Western population ${ }^{[15]}$. Early-generation tyrosine kinase inhibitors (TKIs) have poor penetration to the brain, although they were shown to have variable success in treating BM in a pool analysis ${ }^{[16]}$. Weekly intermittent "pulsatile" administration of high-dose erlotinib (1500 mg/week) in a small retrospective analysis of 9 patients exhibited an ICRR of $67 \%$, with median time to progression of merely 2.7 months ${ }^{[17]}$. The 3 rdgeneration TKI represented by osimertinib, was designed to overcome resistant EGFR mutation T790M and was found to have better permeability in brain. In a pooled analysis of two phase 2 trials, 50 patients with 
T790M positive NSCLC with BM were treated with $80 \mathrm{mg}$ osimertinib. The ICRR was $54 \%(12 \% \mathrm{CR})$ and the brain disease control rate (DCR) was $92 \% ; 75 \%$ of patients were still in response at 9-month follow-up ${ }^{[18]}$. Osimertinib showed very impressive PFS as well as intracranial control over gefitinib or erlotinib in newly diagnosed NSCLC with EGFR mutation and has been approved for first-line use ${ }^{[19]}$.

Anaplastic lymphoma kinase (ALK) rearrangement defines another subset of mutations in 3\%-5\% of NSCLC. BM has been reported in $24 \%$ of patients upon diagnosis and up to $70 \%$ during the course of disease ${ }^{[2,21]}$. It is not entirely clear that it is due to poor brain penetration of first-generation TKI, crizotinib, or that the brain is the preferential site of metastasis of ALK + NSCLC. Second-generation ALK TKIs such as ceritinib, brigatinib and alectinib all showed much better brain penetration and great activity against BM. In ALEX trial, a subset of ALK+ NSCLC patients with measurable CNS lesions at baseline were treated with alectinib vs. crizotinib. The ICRR and PFS were $81 \%, 50 \%$ and 17.3 months, 5.5 months, respectively ${ }^{[22]}$. Moreover, $45 \%$ of the patients with $\mathrm{BM}$ (measurable or nonmeasurable) treated with alectinib achieved $\mathrm{CR}^{[22]}$. Thus, alectinib represents a great treatment option for patients with ALK + NSCLC presenting with BM.

\section{IMMUNOTHERAPY AND NSCLC}

Immune checkpoint inhibitors have transformed the treatment paradigm for advanced-stage NSCLC in both frontline and platinum-resistant settings. These agents inhibit a key inhibitory signaling pathway in $\mathrm{T}$ cell activation by blocking programmed cell death a (PD-1) from binding to the ligand 1 or 2 (PD-L1/PDL2), thereby allowing activation of the inactivated $\mathrm{T}$ cells ${ }^{[23]}$.

\section{Immunotherapy as first-line treatment}

In the pivotal Keynote 024 study, 305 treatment naïve, PD-L1 positive (tumor proportion score, TPS $\geq 50 \%$ ) patients with advanced-stage NSCLC without EGFR, ALK mutations were randomized to receive pembrolizumab, an anti-PD1 monoclonal antibody vs. platinum-based chemotherapy. Pembrolizumab was associated with higher ORR (44.8\% vs. 27.8\%) and prolonged median PFS (10.3 months vs. 6.0 months) ${ }^{[24]}$. Based on this study, the FDA approved the use of pembrolizumab in PDL1 positive patients with advanced-stage NSCLC in frontline setting.

Combinations of immunotherapy with chemotherapy or another immunotherapy agent have also been extensively studied in the past few years. Keynote 189 was another landmark study that confirmed the result of the previously published small phase 2 study on first-line chemo-immunotherapy with carboplatin/ pemetrexed/pembrolizumab in previous untreated non-squamous NSCLC patients ${ }^{[25,26]}$. 616 patients were randomly assigned in a 2:1 ratio, to receive pemetrexed and a platinum-based drug plus either pembrolizumab or placebo every 3 weeks for 4 cycles, followed by pembrolizumab or placebo plus pemetrexed maintenance. The Pembrolizumab-combination group was demonstrated to have a better RR ( $47.6 \%$ vs. $18.9 \%$ ), a longer PFS (8.8 months vs. 4.9 months) and median OS (not reached $v s .11 .3$ months). The benefit was seen in all subgroups, including those with a PD- 1 TPS $<1 \%$. The RR was highest in patients with PD-1 TPS $\geq$ $50 \%(61.4 \% \text { vs. } 22.9 \%)^{[26]}$. Thus, there are two FDA-approved options for NSCLC in the first-line setting at this time. For metastatic squamous NSCLC, platinum/taxane with or without pembrolizumab was investigated in Keynote 407 study. The ORR was 58.4\% in the pembrolizumab-chemotherapy group compared with 35\% in the chemotherapy group. OS was 15.9 months $v s .11 .3$ months, respectively. PFS was observed in all PD-L1 TPS subgroups, although the PD-L1 high subgroup had a much longer PFS (8 months vs. 4.2 months). The platinum/taxane/pembrolizumab combination represents a new standard of care in metastatic squamous $\mathrm{NSCLC}^{[27]}$. Immuno-immunotherapy combination is also under intense investigation. In the Checkmate 227 study, ORR and PFS among patients with a high tumor mutational burden (TMB) defined by at least 10 mutations per megabase was $45.3 \%$ and 7.2 months in the immuno-immunotherapy combination group with nivolumab plus ipilimumab irrespective of PD-L1 expression level. The response was more durable, with $68 \%$ of patients having an ongoing response after 1 year with combination group $v s .25 \%$ with chemotherapy ${ }^{[28]}$. 
Thus, nivolumab plus ipilimumab may represent a new treatment option in metastatic NSCLC with high TMB, though this combination has not been approved to be used clinically.

\section{Immunotherapy as second-line treatment}

Currently there are three agents available in the platinum-resistant setting. Two large phase 3 randomized clinical trials made head-to-head comparison between nivolumab and docetaxel ${ }^{[29,30]}$. Checkmate 057 included patients with non-squamous histology, and Checkmate 017 included patients with squamous histology with identical trial design ${ }^{[29,30]}$. Both trials showed superiority of nivolumab in ORR, PFS and OS as well as significant improvement in quality of life ${ }^{[29,30]}$. Nivolumab was reported to benefit both PD-L1 negative and positive groups with a different antibody, and was approved for 2nd-line use irrespective of PD-L1 expression based on these two trials. Pembrolizumab was compared with docetaxel in the Keynote 010 study wherein it only included PD-L1 positive patients defined as TPS $\geq 1 \%$. The pembrolizumab arm showed significantly better ORR, PFS, OS with a very favorable side effect profile ${ }^{[31]}$. Thus, pembrolizumab was approved in PDL1 positive NSCLC after platinum-based first-line therapy. Atezolizumab, a monoclonal antibody against PD-L1, was compared directly with docetaxel in a phase 2 and a phase 3 randomized trial with similar results. Although there was no median PFS advantage in the atezolizumab arm, an OS advantage was found in all subgroups, which led to the addition of atezolizumab to the armamentarium against NSCLC in the second-line setting ${ }^{[2,33]}$. The landscape of immunotherapy for NSCLC is rapidly changing. These three agents were all approved before first-line immunotherapy became available. With expected wide use of monoimmunotherapy or chemo-immunotherapy combination in the frontline, there is unmet medical need for immunotherapy to overcome immune resistance in previously treated population.

\section{Immunotherapy in NSCLC with brain metastasis}

The brain was once believed to be an immune privileged organ to actively suppress any immune response. It is now known that the immune response in brain parenchyma is tightly regulated ${ }^{[34]}$. In established brain metastases, the tumor microenvironment is composed of the innate immune system, namely microglia and blood-derived myeloid cells/macrophages; and the adaptive immune system, mainly represented by $\mathrm{T}$ cells ${ }^{[34,35]}$. Brain metastases were shown to have higher PDL-1 expression and lower density of tumor infiltrating lymphocytes (TILs) than the matched NSCLC primary tumors ${ }^{[36]}$. The immunogenicity of the primary tumor probably influences the T cell response in brain metastases as denser TILs were observed in melanoma-derived brain metastases followed by renal cell carcinoma and NSCLC ${ }^{[37]}$. The density of TILs seems to correlate well with extent of brain edema and $\mathrm{OS}^{[37]}$. Therefore, the preconditions in the tumor microenvironment to respond to immunotherapy are present in BM.

Patients with active BM from NSCLC have been excluded from pivotal clinical trials of immunotherapy in NSCLC, thus there is no high-level evidence available from the prospective studies. However, in the Keynote 24, the Keynote 189 (trials of pembrolizumab in the frontline), and the OAK trial (atezolizumab in the second-line setting), patients with previously treated brain metastasis were allowed to be enrolled. Specific intracranial response was not available, but the OS benefit seemed to have been equally sustained ${ }^{[2,32,38]}$. The expanded access program (EAP) of nivolumab in Italy included a cohort of 409 NSCLC patients with symptomatic or controlled BM. The real-world experience demonstrated ORR of $17 \%$ and DCR of $40 \%$ respectively, similar to the whole population of 1588 patients with median OS of 8.6 months and 11.3 months, respectively ${ }^{[39]}$. These results seem to suggest the overall benefit was able to be retained in the subgroup of patients with BM. However, it remains unknown from these trials to what extent the intracranial control derives directly from immunotherapy.

In a retrospective study, 43 NSCLC patients with BM were included, and 16 patients had active BM. Patients treated with nivolumab achieved an ICRR and an extracranial RR of $9 \%$ and $11 \%$, respectively. The median intracranial and the general PFS were 3.9 months and 2.8 months, respectively ${ }^{[40]}$. Although the RR was rela- 
tively low, these were real-world unselected cases without known PD-L1 status and the PFS was in line with pivotal immunotherapy trials in the 2nd-line setting. More importantly, the RR appears to be equivalent for both intracranial and extracranial disease.

The single-agent activity of pembrolizumab in the brain was also studied in a phase II trial including both NSCLC and melanoma patients with at least $1 \mathrm{BM}$ between 5 and $20 \mathrm{~mm}$ that was asymptomatic and either untreated or progressing after prior local therapy. The result was recently updated at 2018 ASCO annual meeting $^{[41,42]}$. Two cohorts of NSCLC patients were enrolled with $34 \mathrm{PD}-\mathrm{L} 1$ positive (PD-L1 $\geq 1 \%$ ) patients in cohort 1, and 5 PD-L1 negative or unevaluable patients in cohort 2. Pembrolizumab $10 \mathrm{mg} / \mathrm{kg}$ was administered every 2 weeks. None of the patients had previously received immunotherapy. 10 of 34 (29.4\%) patients in cohort 1 had a response in CNS. Interestingly, 7 patients had discordance between CNS and systemic responses (4 with PD in brain and PR in body, and 3 with PR in brain and PD in body). Intracranial PFS among patients with BM response or stable disease was 10.7 months. Median OS among all patients was 8.9 months, with $31 \%$ of patients living at least 2 years. No patients in cohort 2 had a BM response, but 2 of the 5 patients lived past 1 year. Treatment was well-tolerated, with no neurologic adverse events (AEs) > grade 1 related to treatment, although 2 patients developed grade 3 pneumonitis related to pembrolizum$\mathrm{ab}^{[42]}$. Although large prospective studies are lacking, taken together, it appears that a PD1 inhibitor can have activity in brain and may be a safe and active treatment option for patients with small, asymptomatic BM in NSCLC patients.

The role of immunotherapy has been more extensively studied in melanoma patients with BM. Ipilimumab, a CTLA4 inhibitor, achieved intracranial disease control in 12/51 (24\%) patients in patients with asymptomatic small BM without steroid use ${ }^{[43]}$. More recently, two phase 2 studies combining nivolumab and ipilimumab were investigated in the same patient population. The Checkmate 204 study comprised shortterm follow-up of 75 asymptomatic patients. The ICRR was $56 \%$ with $20 \%$ of patients experiencing $\mathrm{CR}^{[44]}$. In an Austrialian study, 35 and 25 patients with asymptomatic BM and no previous immunotherapy were randomized to cohort A (nivolumab plus ipilimumab) and B (nivolumab only), respectively. 16 patients in whom local therapy had failed or who had neurological symptoms or leptomeningeal disease were enrolled in cohort $\mathrm{C}^{[45]}$. The ICRR, CR for cohort A was $46 \%$ and $17 \%$, respectively. The median intracranial PFS was not reached at data cutoff. Of note, for treatment-naïve patients, the ICRR was $56 \%$. By contrast, the cohort B of 25 patients receiving nivolumab only had ICRR of $20 \%$ and CR of $12 \%$, respectively with median intracranial PFS of 2.5 months $^{[45]}$. In contrast to cohort A and B, only one of 16 patients in cohort $\mathrm{C}$ had intracranial response $(6 \%)$ and this patient had BRAF wild type, no leptomeningeal disease and neurological symptoms only $^{[45]}$. As expected, more treatment-related adverse events (AEs) happened in cohort A patients who received combination. Three patients (9\%) in cohort A and one patient in cohort C (6\%) developed peripheral neuropathy. Grade 3 AEs occurred in $54 \%$ of cohort A, $16 \%$ of cohort B and $13 \%$ of cohort C and the most common AEs were diarrhea or colitis, and hepatitis. Three patients in cohort A experienced grade 4 hepatitis, pulmonary edema or hypophysitis. One patient in cohort B and one patient in cohort C experience severe headache due to cerebral edema. No death occurred because of study treatment ${ }^{[45]}$. No CNS demyelination occurred, although it was reported previously in a patient treated with nivolumab after progressing on ipilimumab ${ }^{[46]}$. These results suggest that combination immunotherapy with ipilimumab and nivolumab may represent a valuable option in patients with asymptomatic melanoma brain metastases, long-term follow-up with OS data is eagerly awaited ${ }^{[45]}$.

\section{FUTURE PERSPECTIVE}

In general, the response of systemic (extra-cranial) disease correlates well with that of intracranial BM with immunotherapy although discordance has been reported ${ }^{[42,45]}$. Using the available biomarkers, we might be able to tease out the patients with asymptomatic small BM who might respond well to immunotherapy or an immunotherapy combination. At this time, there are no data demonstrating the use of combination immu- 
notherapy in NSCLC with BM. However, as aforementioned, the Checkmate 227 study exhibited great activity of nivolumab-ipilimumab combination against NSCLC with high $\mathrm{TMB}^{[28]}$. Extrapolating from melanoma studies, it is conceivable that the same combination might be able to confer a much higher and more durable response in NSCLC with BM and high TMB. In the Keynote 189 trial using platinum/pemetrexed/pembrolizumab, the hazard ratio in the subgroup of 108 patients with BM was impressive 0.36 , suggesting chemo-immunotherapy could represent an effective option for this group, although PDL1 status was unknown ${ }^{[26]}$. For the PD-L1 $\geq 50 \%$ subgroup, the RR was over $60 \%$, with a disease control rate almost up to $90 \%{ }^{[26]}$. This treatment combination might also provide a great ICRR and durable IC PFS given that both chemotherapy and immunotherapy have been shown to be effective against BM in NSCLC. Furthermore, how to incorporate and/or sequence SRS in the context of immunotherapy remains unanswered. Prospective studies are needed to address these burning questions, and future adoption of immunotherapy or immunotherapy combinations as the first-line therapy in the appropriate patient population with BM may change our current clinical practice and the use of WBRT or SRT.

\section{DECLARATIONS}

\section{Authors' contributions}

Design: Niu J

Literature research, data analysis, manuscript writing and editing: Niu J, Zhou J, Lindebak S, Mahmoud F Manuscript revision: Niu J

\section{Availability of data and materials}

Not applicable.

\section{Financial support and sponsorship}

None.

\section{Conflicts of interest}

All authors declared that there are no conflicts of interest.

\section{Ethical approval and consent to participate}

Not applicable.

\section{Consent for publication}

Not applicable.

\section{Copyright}

(c) The Author(s) 2018.

\section{REFERENCES}

1. Torre LA, Bray F, Siegel RL, Ferlay J, Lortet-Tieulent J, Jemal A. Global cancer statistics, 2012. CA Cancer J Clin 2015;65:87-108.

2. Siegel RL, Miller KD, Jemal A. Cancer statistics, 2018. CA Cancer J Clin 2018;68:7-30.

3. Waqar SN, Waqar SH, Trinkaus K, Gadea CA, Robinson CG, Bradley J, Watson MA, Puri V, Govindan R, Morgensztern D. Brain metastases at presentation in patients with non-small cell lung cancer. Am J Clin Oncol 2018;41:36-40.

4. Dawe DE, Greenspoon JN, Ellis PM. Brain metastases in non-small-cell lung cancer. Clin Lung Cancer 2014;15:249-57.

5. Davis FG, Dolecek TA, McCarthy BJ, Villano JL. Toward determining the lifetime occurrence of metastatic brain tumors estimated from 2007 United States cancer incidence data. Neuro Oncol 2012;14:1171-7.

6. Schabath MB, Thompson ZJ, Gray JE. Temporal trends in demographics and overall survival of non-small-cell lung cancer patients at Moffitt Cancer Center from 1986 to 2008. Cancer Control 2014;21:51-6.

7. Gaspar L, Scott C, Rotman M, Asbell S, Phillips T, Wasserman T, McKenna WG, Byhardt R. Recursive partitioning analysis (RPA) of prognostic factors in three Radiation Therapy Oncology Group (RTOG) brain metastases trials. Int J Radiat Oncol Biol Phys 1997;37:745-51.

8. Kalkanis SN, Kondziolka D, Gaspar LE, Burri SH, Asher AL, Cobbs CS, Ammirati M, Robinson PD, Andrews DW, Loeffler JS, Mc- 
Dermott M, Mehta MP, Mikkelsen T, Olson JJ, Paleologos NA, Patchell RA, Ryken TC, Linskey ME. The role of surgical resection in the management of newly diagnosed brain metastases: a systematic review and evidence-based clinical practice guideline. J Neurooncol 2010;96:33-43.

9. Mulvenna P, Nankivell M, Barton R, Faivre-Finn C, Wilson P, McColl E, Moore B, Brisbane I, Ardron D, Holt T, Morgan S, Lee C, Waite K, Bayman N, Pugh C, Sydes B, Stephens R, Parmar MK, Langley RE. Dexamethasone and supportive care with or without whole brain radiotherapy in treating patients with non-small cell lung cancer with brain metastases unsuitable for resection or stereotactic radiotherapy (QUARTZ): results from a phase 3, non-inferiority, randomised trial. Lancet 2016;388:2004-14.

10. Tsao M, Xu W, Sahgal A. A meta-analysis evaluating stereotactic radiosurgery, whole-brain radiotherapy, or both for patients presenting with a limited number of brain metastases. Cancer 2012;118:2486-93.

11. Yamamoto M, Serizawa T, Higuchi Y, Sato Y, Kawagishi J, Yamanaka K, Shuto T, Akabane A, Jokura H, Yomo S, Nagano O, Aoyama H. A multi-institutional prospective observational study of stereotactic radiosurgery for patients with multiple brain metastases (JLGK0901 study update): irradiation-related complications and long-term maintenance of mini-mental state examination scores. Int J Radiat Oncol Biol Phys 2017;99:31-40.

12. Brown PD, Ballman KV, Cerhan JH, Anderson SK, Carrero XW, Whitton AC, Greenspoon J, Parney IF, Laack NNI, Ashman JB, Bahary JP, Hadjipanayis CG, Urbanic JJ, Barker FG 2nd, Farace E, Khuntia D, Giannini C, Buckner JC, Galanis E, Roberge D. Postoperative stereotactic radiosurgery compared with whole brain radiotherapy for resected metastatic brain disease (NCCTG N107C/CEC.3): a multicentre, randomised, controlled, phase 3 trial. Lancet Oncol 2017;18:1049-60.

13. Barlesi F, Gervais R, Lena H, Hureaux J, Berard H, Paillotin D, Bota S, Monnet I, Chajara A, Robinet G. Pemetrexed and cisplatin as first-line chemotherapy for advanced non-small-cell lung cancer (NSCLC) with asymptomatic inoperable brain metastases: a multicenter phase II trial (GFPC 07-01). Ann Oncol 2011;22:2466-70.

14. Bailon O, Chouahnia K, Augier A, Bouillet T, Billot S, Coman I, Ursu R, Belin C, Zelek L, Des Guetz G, Levy C, Carpentier AF, Morere JF. Upfront association of carboplatin plus pemetrexed in patients with brain metastases of lung adenocarcinoma. Neuro Oncol 2012;14:491-5.

15. Lynch TJ, Bell DW, Sordella R, Gurubhagavatula S, Okimoto RA, Brannigan BW, Harris PL, Haserlat SM, Supko JG, Haluska FG, Louis DN, Christiani DC, Settleman J, Haber DA. Activating mutations in the epidermal growth factor receptor underlying responsiveness of non-small-cell lung cancer to gefitinib. N Engl J Med 2004;350:2129-39.

16. Fan Y, Xu X, Xie C. EGFR-TKI therapy for patients with brain metastases from non-small-cell lung cancer: a pooled analysis of published data. Onco Targets Ther 2014;7:2075-84.

17. Grommes C, Oxnard GR, Kris MG, Miller VA, Pao W, Holodny AI, Clarke JL, Lassman AB. "Pulsatile" high-dose weekly erlotinib for CNS metastases from EGFR mutant non-small cell lung cancer. Neuro Oncol 2011;13:1364-9.

18. Goss G, Tsai CM, Shepherd FA, Ahn MJ, Bazhenova L, Crino L, de Marinis F, Felip E, Morabito A, Hodge R, Cantarini M, Johnson M, Mitsudomi T, Janne PA, Yang JC. CNS response to osimertinib in patients with T790M-positive advanced NSCLC: pooled data from two phase II trials. Ann Oncol 2018;29:687-93.

19. Soria JC, Ohe Y, Vansteenkiste J, Reungwetwattana T, Chewaskulyong B, Lee KH, Dechaphunkul A, Imamura F, Nogami N, Kurata T, Okamoto I, Zhou C, Cho BC, Cheng Y, Cho EK, Voon PJ, Planchard D, Su WC, Gray JE, Lee SM, Hodge R, Marotti M, Rukazenkov Y, Ramalingam SS. Osimertinib in untreated EGFR-mutated advanced non-small-cell lung cancer. N Engl J Med 2018;378:113-25.

20. Doebele RC, Lu X, Sumey C, Maxson DA, Weickhardt AJ, Oton AB, Bunn PA, Jr., Baron AE, Franklin WA, Aisner DL, VarellaGarcia M, Camidge DR. Oncogene status predicts patterns of metastatic spread in treatment-naive nonsmall cell lung cancer. Cancer 2012;118:4502-11.

21. Rangachari D, Yamaguchi N, VanderLaan PA, Folch E, Mahadevan A, Floyd SR, Uhlmann EJ, Wong ET, Dahlberg SE, Huberman MS, Costa DB. Brain metastases in patients with EGFR-mutated or ALK-rearranged non-small-cell lung cancers. Lung Cancer 2015;88:10811.

22. Peters S, Camidge DR, Shaw AT, Gadgeel S, Ahn JS, Kim DW, Ou SI, Perol M, Dziadziuszko R, Rosell R, Zeaiter A, Mitry E, Golding $\mathrm{S}$, Balas B, Noe J, Morcos PN, Mok T. Alectinib versus crizotinib in untreated ALK-positive non-small-cell lung cancer. N Engl J Med 2017;377:829-38.

23. Fife BT, Bluestone JA. Control of peripheral T-cell tolerance and autoimmunity via the CTLA-4 and PD-1 pathways. Immunol Rev 2008;224:166-82.

24. Reck M, Rodriguez-Abreu D, Robinson AG, Hui R, Csoszi T, Fulop A, Gottfried M, Peled N, Tafreshi A, Cuffe S, O’Brien M, Rao S, Hotta K, Leiby MA, Lubiniecki GM, Shentu Y, Rangwala R, Brahmer JR. Pembrolizumab versus chemotherapy for PD-L1-positive non-small-cell lung cancer. N Engl J Med 2016;375:1823-33.

25. Langer CJ, Gadgeel SM, Borghaei H, Papadimitrakopoulou VA, Patnaik A, Powell SF, Gentzler RD, Martins RG, Stevenson JP, Jalal SI, Panwalkar A, Yang JC, Gubens M, Sequist LV, Awad MM, Fiore J, Ge Y, Raftopoulos H, Gandhi L. Carboplatin and pemetrexed with or without pembrolizumab for advanced, non-squamous non-small-cell lung cancer: a randomised, phase 2 cohort of the open-label KEYNOTE-021 study. Lancet Oncol 2016;17:1497-508.

26. Gandhi L, Rodriguez-Abreu D, Gadgeel S, Esteban E, Felip E, De Angelis F, Domine M, Clingan P, Hochmair MJ, Powell SF, Cheng SY, Bischoff HG, Peled N, Grossi F, Jennens RR, Reck M, Hui R, Garon EB, Boyer M, Rubio-Viqueira B, Novello S, Kurata T, Gray JE, Vida J, Wei Z, Yang J, Raftopoulos H, Pietanza MC, Garassino MC. Pembrolizumab plus chemotherapy in metastatic non-small-cell lung cancer. N Engl J Med 2018;378:2078-92.

27. Paz-Ares LG, Luft A, Tafreshi A, Gumus M, Mazieres J, Hermes B, Senler FC, Fülöp A, Rodriguez-Cid J, Sugawara S, Cheng Y, Novello S, Halmos B, Shentu Y, Kowalski D. Phase 3 study of carboplatin-paclitaxel/nab-paclitaxel (Chemo) with or without pembrolizumab (Pembro) for patients (Pts) with metastatic squamous (Sq) non-small cell lung cancer (NSCLC). J Clin Oncol 2018;36 suppl:abstr105.

28. Hellmann MD, Ciuleanu TE, Pluzanski A, Lee JS, Otterson GA, Audigier-Valette C, Minenza E, Linardou H, Burgers S, Salman P, Borghaei H, Ramalingam SS, Brahmer J, Reck M, O’Byrne KJ, Geese WJ, Green G, Chang H, Szustakowski J, Bhagavatheeswaran P, 
Healey D, Fu Y, Nathan F, Paz-Ares L. Nivolumab plus ipilimumab in lung cancer with a high tumor mutational burden. N Engl J Med 2018;378:2093-104.

29. Borghaei H, Paz-Ares L, Horn L, Spigel DR, Steins M, Ready NE, Chow LQ, Vokes EE, Felip E, Holgado E, Barlesi F, Kohlhaufl M, Arrieta O, Burgio MA, Fayette J, Lena H, Poddubskaya E, Gerber DE, Gettinger SN, Rudin CM, Rizvi N, Crino L, Blumenschein GR, Jr., Antonia SJ, Dorange C, Harbison CT, Graf Finckenstein F, Brahmer JR. Nivolumab versus docetaxel in advanced nonsquamous non-small-cell lung cancer. N Engl J Med 2015;373:1627-39.

30. Brahmer J, Reckamp KL, Baas P, Crino L, Eberhardt WE, Poddubskaya E, Antonia S, Pluzanski A, Vokes EE, Holgado E, Waterhouse D, Ready N, Gainor J, Aren Frontera O, Havel L, Steins M, Garassino MC, Aerts JG, Domine M, Paz-Ares L, Reck M, Baudelet C, Harbison CT, Lestini B, Spigel DR. Nivolumab versus docetaxel in advanced squamous-cell non-small-cell lung cancer. N Engl J Med 2015;373:123-35.

31. Herbst RS, Baas P, Kim DW, Felip E, Perez-Gracia JL, Han JY, Molina J, Kim JH, Arvis CD, Ahn MJ, Majem M, Fidler MJ, de Castro G, Jr., Garrido M, Lubiniecki GM, Shentu Y, Im E, Dolled-Filhart M, Garon EB. Pembrolizumab versus docetaxel for previously treated, PD-L1-positive, advanced non-small-cell lung cancer (KEYNOTE-010): a randomised controlled trial. Lancet 2016;387:1540-50.

32. Rittmeyer A, Barlesi F, Waterkamp D, Park K, Ciardiello F, von Pawel J, Gadgeel SM, Hida T, Kowalski DM, Dols MC, Cortinovis DL, Leach J, Polikoff J, Barrios C, Kabbinavar F, Frontera OA, De Marinis F, Turna H, Lee JS, Ballinger M, Kowanetz M, He P, Chen DS, Sandler A, Gandara DR. Atezolizumab versus docetaxel in patients with previously treated non-small-cell lung cancer (OAK): a phase 3, open-label, multicentre randomised controlled trial. Lancet 2017;389:255-65.

33. Fehrenbacher L, Spira A, Ballinger M, Kowanetz M, Vansteenkiste J, Mazieres J, Park K, Smith D, Artal-Cortes A, Lewanski C, Braiteh F, Waterkamp D, He P, Zou W, Chen DS, Yi J, Sandler A, Rittmeyer A. Atezolizumab versus docetaxel for patients with previously treated non-small-cell lung cancer (POPLAR): a multicentre, open-label, phase 2 randomised controlled trial. Lancet 2016;387:1837-46.

34. Berghoff AS, Venur VA, Preusser M, Ahluwalia MS. Immune checkpoint inhibitors in brain metastases: from biology to treatment. Am Soc Clin Oncol Educ Book 2016;35:e116-22.

35. Fridman WH, Pages F, Sautes-Fridman C, Galon J. The immune contexture in human tumours: impact on clinical outcome. Nat Rev Cancer 2012;12:298-306.

36. Berghoff AS, Ricken G, Wilhelm D, Rajky O, Widhalm G, Dieckmann K, Birner P, Bartsch R, Preusser M. Tumor infiltrating lymphocytes and PD-L1 expression in brain metastases of small cell lung cancer (SCLC). J Neurooncol 2016;130:19-29.

37. Berghoff AS, Fuchs E, Ricken G, Mlecnik B, Bindea G, Spanberger T, Hackl M, Widhalm G, Dieckmann K, Prayer D, Bilocq A, Heinzl H, Zielinski C, Bartsch R, Birner P, Galon J, Preusser M. Density of tumor-infiltrating lymphocytes correlates with extent of brain edema and overall survival time in patients with brain metastases. Oncoimmunology 2016;5:e1057388.

38. Reck M. Pembrolizumab as first-line therapy for metastatic non-small-cell lung cancer. Immunotherapy 2018;10:93-105.

39. Crinò L, Bidoli P, Ulivi P, Minenza E, Cortesi E, Garassino M, Cappuzzo F, Grossi F, Tonini G, Sarobba MG, Pinotti G, Numico G, Samaritani R, Ciuffreda L, Frassoldati A, Bregni MB, Santo A, Piantedosi F, Illiano A, De Marinis F, Delmonte A. Italian Nivolumab Expanded Access Programme (EAP): data from patients with advanced non-squamous NSCLC and brain metastases. J Thoracic Oncol 2017;12:S1915.

40. Gauvain C, Vauleon E, Chouaid C, Lerhun E, Jabot L, Scherpereel A, Vinas F, Cortot AB, Monnet I. Intracerebral efficacy and tolerance of nivolumab in non-small-cell lung cancer patients with brain metastases. Lung Cancer 2018;116:62-6.

41. Goldberg SB, Gettinger SN, Mahajan A, Chiang AC, Herbst RS, Sznol M, Tsiouris AJ, Cohen J, Vortmeyer A, Jilaveanu L, Yu J, Hegde U, Speaker S, Madura M, Ralabate A, Rivera A, Rowen E, Gerrish H, Yao X, Chiang V, Kluger HM. Pembrolizumab for patients with melanoma or non-small-cell lung cancer and untreated brain metastases: early analysis of a non-randomised, open-label, phase 2 trial. Lancet Oncol 2016;17:976-83.

42. Goldberg SB, Gettinger SN, Mahajan A, Herbst RS, Chiang AC, Lilenbaum R, Jilaveanu L, Rowen E, Gerrish H, Komlo A, Wei W, Chiang V, Kluger HM. Durability of brain metastasis response and overall survival in patients with non-small cell lung cancer (NSCLC) treated with pembrolizumab. J Clin Oncol 2018;36 suppl:abstr2009.

43. Margolin K, Ernstoff MS, Hamid O, Lawrence D, McDermott D, Puzanov I, Wolchok JD, Clark JI, Sznol M, Logan TF, Richards J, Michener T, Balogh A, Heller KN, Hodi FS. Ipilimumab in patients with melanoma and brain metastases: an open-label, phase 2 trial. Lancet Oncol 2012;13:459-65.

44. Tawbi H, Forsyth P, Algazi A, Hamid O, Hodi FS, Moschos S, Khushalani N, Gonzalez R, Lao C, Postow M, Atkins MB, Ernstoff M, Puzanov I, Kudchadkar R, Thomas R, Tarhini A, Jiang J, Avila A, Demelo S, Margolin K. Efficacy and safety of nivolumab (NIVO) plus ipilimumab (IPI) in patients with melanoma (MEL) metastatic to the brain: results of the phase II study CheckMate 204. J Clin Oncol 2017;35 suppl:abstr9507.

45. Long GV, Atkinson V, Lo S, Sandhu S, Guminski AD, Brown MP, Wilmott JS, Edwards J, Gonzalez M, Scolyer RA, Menzies AM, McArthur GA. Combination nivolumab and ipilimumab or nivolumab alone in melanoma brain metastases: a multicentre randomised phase 2 study. Lancet Oncol 2018;19:672-81.

46. Maurice C, Schneider R, Kiehl TR, Bavi P, Roehrl MH, Mason WP, Hogg D. Subacute CNS Demyelination after treatment with nivolumab for melanoma. Cancer Immunol Res 2015;3:1299-302. 